\title{
Courtship and behavioral maturation of male mouflons
}

\author{
Richard BON*, José M. RECARTE, Georges GONZALEZ \\ and Jean M. CUGNASSE
}

Bon R., Recarte J. M., Gonzalez G. and Cugnasse J. M. 1995. Courtship and behavioral maturation of male mouflons. Acta Theriologica 40: 283-294.

This study fails to find qualitative differences in courtship (ie intra- and intersexual interactions), according to male age in mouflon Ovis gmelini musimon (Pallas, 1811). Conversely, clear age differences arose concerning the proportion of time males dedicated to reproductive and non-reproductive activities. During the rut, males spent less time feeding, and more time scanning and in male-male interactions as age increased. Young males ( $\leq 2$ years old) interacted much less agonistically with other males and courted females twice less than oldest males ( $\geq 7$ years old). So male behavioral maturation does not only depend on age but could also be influenced by demographic constraints, ie presence of old dominant males. The male reproductive effort, however, seemed independent of the presence of old dominant males, which could reflect a developmental constraint. Young males would not have enough energy reserves because of growth to dedicate as much time as mature males to reproduction, even in the absence of these latter.

Departamento de Psicobiologia, Universidad Camplutense de Madrid, Campus de Somosaguas, 28223 Madrid, Spain (RB); Institut de Recherche sur les Grands Mammiferes, Institut National de la Recherche Agronomique, B.P. 27, 31326 Castanet-

-Tolosan, France (JMR present address, GG); Departamento de Biologia Animal (Etologia), Facultad de Ciencias, c/a San Alberto Magno s/n, Universidad de Cordoba, 14004 Cordoba, Spain (JMR); Office National de la Chasse, Centre National de Recherche Appliquée Faune de Montagne, 2 rue H. Dejean, 34800 Clermont-l'Hérault, France (JMC)

Key words: Ovis gmelini, male courtship, behavioral maturation

\section{Introduction}

An increasing number of papers demonstrates the flexibility of mating systems (Lott 1984, Rubenstein 1986, Byers and Kitchen 1988, Langbein and Thirgood 1989, Carranza et al. 1993). Even within the same population, males may use alternative mating strategies in response to ecological changes, female social behavior or intrasexual competition (Hogg 1987, Thirgood 1990, Gosling 1991).

\footnotetext{
* Present address: Departamento de Psicologia Experimental, Centro de Filosofia e Ciências Humanas, Universidade Federal do Pará, 66075-900 Belém (Pará), Brazil. To whom reprint requests should be sent.
} 
Males' reproductive success is based mainly on dominance in rank which increases with age, though this may be reversed in old animals (Clutton-Brock et al. 1979). Generally mature dominant males performed most of the breeding (Gibson and Guinness 1980, Hogg 1987)

However, behavior quality of males and not necessarily age is also a basic condition for reproductive success (Shackleton 1991). For instance, the oldest males with smaller antler size than dominant younger males may use more subtle strategies to enhance their reproductive success (Clutton-Brock et al. 1979). Females would prefer older males, partly because young males use less ritualized courtship and behave more roughly toward them than mature males (Ozoga and Verme 1985, Barrette 1987, Poole 1989). This age-related difference of behavior may be due to competition among males (Hogg 1987). Comparing two bighorn Ovis canadensis populations, Shackleton (1991) found that when old males were removed by hunting, young males exhibited similar mature behavior patterns as used by older males. Conversely, when old males were present, young males used more "juvenile" (agonistic) patterns as classically reported (Geist 1969, Alados 1986, Hogg 1987, Shackleton 1991, Valdez et al. 1991). Alternatively, male courtship may depend upon a maturation program partially independent of extrinsic factors. In this scenario, males would need to reach a threshold age before exhibiting a fully "mature" courtship and reproductive effort.

Young males were suspected of performing a large proportion of mating in Caroux-Espinouse because more than $50 \%$ of mating groups were tended by males 6.5 years old (Bon et al. 1992). It is frequently reported that young males spend less time in mating activities when large dominant males control most of the matings (Alados 1986, Maher and Byers 1987). A cost-benefit approach predicts that young males would suffer high a risk in intra-sexual competition with older males. However, young dominant males use alternative strategies in their attempts to mate (Hogg 1984). When old dominant males are absent or in low proportion, young males could increase their time dedicated to courtship as suggested by an increase of male-male competition (Rubenstein 1986, Byers and Kitchen 1988). Heimer et al. (1984) suggested that removal of oldest rams in Dall sheep Ovis dalli populations lowered the age at which ram mortality increased. Ideally, the reproductive success of males should be measured by the number of offspring fathered. But this data is hard to obtain in nature. An index of male reproductive effort is made to assess the involvement of males in intrasexual competition and courtship relative to other activities.

The behavior of males in intra-sex interactions and courtship was examined. We expect a maturation effect on male behavior, in particular a higher proportion of agressive acts by young males and a higher proportion of displays by old males. Secondly, the reproductive effort of males was evaluated. Thirdly, because we found few large males, younger males were suspected to have increased their involvment in reproductive activities as a result of lower competition. 


\section{Study area and methods}

The Caroux-Espinouse massif $\left(42^{\circ} \mathrm{N}, 3^{\circ} \mathrm{E}\right.$, South of France) has been presented before (Bon et al. 1992). The study was conducted in October 1987, from 15 October to 3 November and from 11 to 28 November 1988 in a N-S oriented valley (Vialais) covering 800 ha and protected from hunting. The slopes of the valley range from $600 \mathrm{~m}$ to $1100 \mathrm{~m}$ altitude. Woods occupy $28 \%$ and rocks $8 \%$ of the surface. The vegetation in open areas is dominated by moorlands of heathers (Erica cinrea, Calluna vulgaris) and broom (Sarothamnus scoparius, Genista purgans), frequently mixed with graminaceous species and bilberry (Vaccinium myrtillus).

Vialais valley was used year-round by females, while males were only present during the rut and early winter. This valley is a part of an area ( $1830 \mathrm{ha}$ ) protected from hunting, and represents a small part of the mouflon's total area (13000 ha). Equal numbers of males and females were removed by hunting from 1977 to 1988 , but the mean age of males harvested each hunting season (range 5-6.6 years old) exceeded that of females (range 3.1-4.5) (J. M. Cugnasse, unpubl.). The estimated age of oldest males was 13 years old and 14 years old for females. Male age was estimated by horn size and growth annuli when detectable. However, precise determination is impossible in nature so that 5 age classes were considered: yearling, 2.5-year-old, 3.5- to 4.5-year-old, 5.5- to 6.5-year-old, and $\geq 7.5$ years old rams.

Tending groups composed of one male and one female were observed from mid-October to the beginning of December. Of these, $80.5 \%(n=67)$ were seen from mid-October to the end of November (Bon et al. 1992), as confirmed by the cumulative percentage of lamb/ewe ratio (Bon et al. 1993a). Thus, we considered only data from mid-October to end of November, collected in the morning and in the afternoon when most mouflons were feeding. One student noted the composition of all groups seen. Meanwhile, a second continuously recorded animal behavior during 10 min sampling periods (Altmann 1974), using binoculars and spotting scopes. Behavior patterns were classified using previous descriptions of wild sheep (see Cavallini 1987, McClelland 1991, Shackleton 1991, Valdez et al. 1991). Male-male agonistic (or risky) patterns included clash, horn wrestle/butt, shoulder-push, while displays (or dominant) behavior consisted of head-shake, twist, kick, low-stretch, approach, side display (which may be associated with twist), chase away, neck fight, block, head-up or horn threat, stand perpendicular, nose rear, mount or mount intent, receive horn rubbing. Chase may consist of a threat displayed by a dominant male to move away a subordinate, or of a more steady chase performed over several meters. Side display consists in a parallel approach of a male toward another male while presenting horns; males may also stay in parallel stand for several seconds. Submissive behavior (those considered as non ambiguous) were walk/run away, receive neck fight and perform horn rubbing on a dominant male. Male courtship towards females $\geq 1.5$ years old included twist, kick, low-stretch, nose rear, approach and chase after (often in low-stretch), successful mounts and mount intents. Agonistic behavior towards females by males comprised butt, head-up, block, shoulder-push, rush toward. By blocking, males prevent females from walking and by shoulder-push males tried to isolate females in blocking tactics (Hogg 1984). Unsuccessful mount attempts were not classified according to Shackleton (1991) because we were unable to distinguish courtship from "forced copulation".

During focal sampling, "moving" (walking and running), "standing up" and "feeding" were also recorded. "Standing up" included anti-predator behavior, search and observation of conspecifics, standing posture in courting behavior and others. All these categories were grouped because distinguishing them was very difficult.

Despite the short time (10 min) of each focal sampling, many sessions were not completed because males often quit the observation field. Only those samples $>5$ min were retained for the analyses. The mean sampling time was similar between the classes, by increasing order of age: $9.17(n=24)$, $9.00(n=19), 9.27(n=49), 9.43(n=29)$, and $9.30 \mathrm{~min}(n=24)$, representing $25 \mathrm{~h} 48 \mathrm{~min}$. Time dedicated to behavior categories were standardized by dividing the total time dedicated to each category by the total time of each focal sampling. 


\section{Results}

In a previous paper, we showed that males $\geq 7.5$ years old entered female ranges later than younger males (Bon et al. 1992; Fig. 1). The oldest males left the rutting grounds by the second half of November, while males 3 to 6 yrs old did so later. The proportions of younger males relative to females stayed almost stable, but their proportions relative to older males increased.
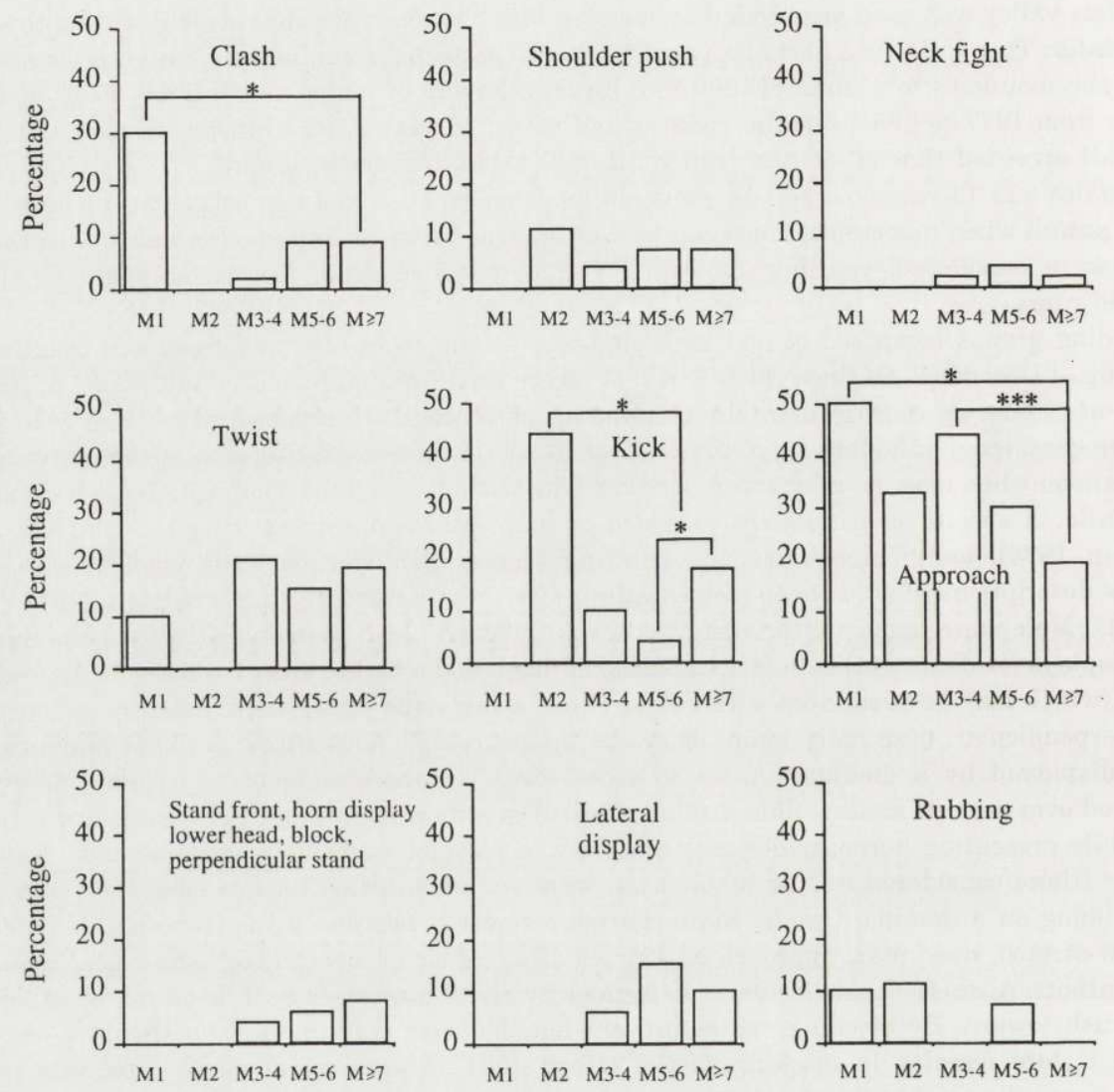

Fig. 1. Comparison of male-male interactions patterns between age classes of mouflons during 1987-1988 rutting periods, in Caroux-Espinouse (Southern France). (G-test: ${ }^{*}-p<0.05,{ }^{* *}-p<$ $0.01, * * *-p<0.001)$.

\section{Behavior components as related to male age}

Male-male interactions represented a low proportion of all interactions for yearling $(n=103)$ and 2.5 year old males $(n=76)$, ie $10 \%$ and $12 \%$ respectively. 
Relative frequencies of male-male interactions increased with age, especially for the oldest ones, ie $17 \%(n=286), 19 \%(n=282)$ and $60 \%(n=369)$ respectively.

Some male-male interaction patterns such as clash, head-shake and head-up were relatively rare, and some behaviors were grouped into larger categories. The very low proportions of intra-sex interactions performed by males $\leq 2$ years old do not allow accurate comparisons among all age classes. However, there were no clear indications that young males performed more agonistic patterns than old ones. Very few qualitative differences were found between the three older male classes. Males 5-6 yrs old performed less kick than males $\geq 7$ yrs old ( $4 \%$ vs $18 \%$ ) and males 3-4 yrs old did less approach/chase/pursue than males $\geq 7.5$ yrs of age (44\% vs $19 \%$; Fig. 1 ).

For all age classes, the observed frequencies of submissive, dominant and risk categories differed from expected $\left(\chi^{2}\right.$-tests, all $\left.p<0.01\right)$. Males were involved less in submissive behaviors and more in dominant activities as they aged (Fig. 2). The relative proportion of submission patterns exhibited by each class was not related to age (respectively $37,18,20,24$ and 1\%). Rubbing, for instance, were seen to be performed by yearlings (10\%), 2 year olds (11\%) and males $5-6$ yrs old $(7 \%)$. Older males were the only individuals trying to mount others. Males also took more risks as they aged, although significant differences were found only
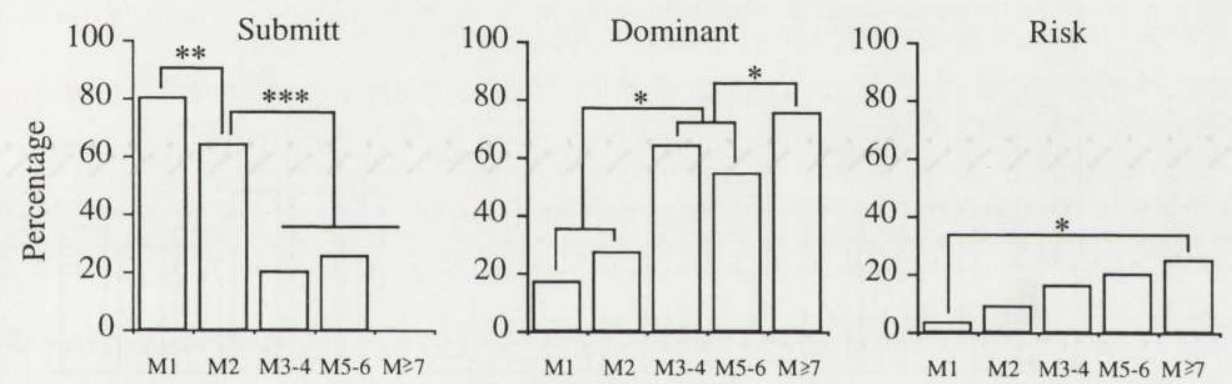

Fig. 2. Comparison of age classes for the male-male interaction classes, submitt, dominant and risks. $\left(G\right.$-test: $\left.{ }^{*}-p<0.05, * *-p<0.01, * * *-p<0.001\right)$.

Table 1. Distribution of male-male interaction classes, submissive, dominant and risk behaviors related to age class difference.

\begin{tabular}{llllllr}
\hline \multirow{2}{*}{ Behaviour class } & \multicolumn{5}{c}{ Age class differences } \\
\cline { 2 - 7 } & $0(\%)$ & $1(\%)$ & $2(\%)$ & $3(\%)$ & $4(\%)$ & $n$ \\
\hline Submissive & 32 & 14.5 & 38.5 & 13 & 1 & 75 \\
Dominant & 68 & 21.5 & 13 & 8 & 1.5 & 243 \\
Risk & 75.5 & 23 & 1 & 0 & 0 & 86 \\
\hline
\end{tabular}


between yearlings and males $\geq 7 \mathrm{yrs}$ old. Most dominant and risky behaviors were performed by males $\geq 3$ yrs old, especially the oldest ones (dominant: $2,2,17.5$, $13.5,64 \%$ and risk: $1,2,14,16,66.5 \%$ respectively). Interactions involved animals rather close in age but the distribution differed between the categories (Table 1). Submissive behavior patterns involved males with a large range of age difference, although yearlings were rarely seen to avoid males $\geq 7 \mathrm{yrs}$ old simply because they seldom interacted together. Dominant behavior patterns were more restricted but less so than "risky" behaviors that involved individuals of similar age,

Males $\leq 6.5$ yrs old interacted more frequently with females than with males $\left(\chi^{2}\right.$-tests, all $\left.p<0.001, \mathrm{df}=1\right)$, while males $\geq 7.5$ yrs old did the opposite $(p<$
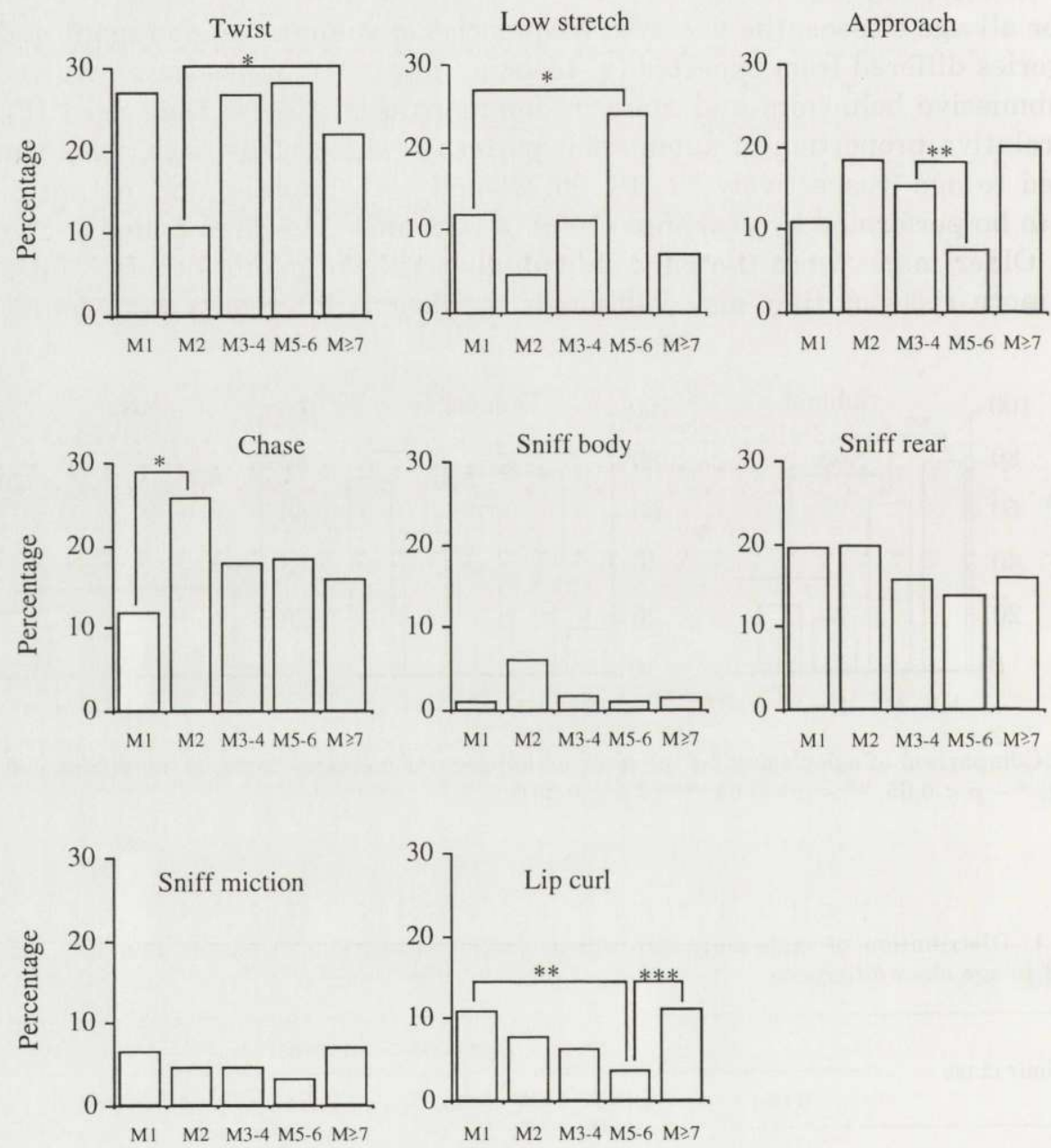

Fig. 3. Comparison of male-female interaction patterns between male age classes. ( $G$-test: ${ }^{*}-p<0.05$, $* *-p<0.01, * * *-p<0.001)$ 
$0.001, \mathrm{df}=1$ ). On the other hand, the rate of male-female interactions increased with male age, respectively $0.31,0.28,0.47,0.79$ and $0.64 / \mathrm{min}$. "Kick females" were rarely observed during this study as opposed to "kick males". Males rarely performed agonistic acts towards females $(n=8)$, and these involved only males $<7$ yrs old. Head butt was performed only by males $\leq 4.5$ yrs old. Rush towards ewes was performed only by males 3 to 6 yrs old in three focal sessions, while blocking ewes was seen on only two occasions, by males $5-6$ yrs old. Few significant differences were found among age classes when considering others acts and no patterns related to age were found (Fig. 3). Males 2 yrs old performed twist, low stretch less often but chased females more often than other males. Males 5-6 yrs old performed low-stretch more and approached females less often than others. The percentage of lip curl decreased from yearling to males 5-6 yrs old but increased for males $\geq 7$ yrs old to a level similar to yearlings. This latter behavior may reflect a maturation effect of males. Males would increasingly exhibit it in appropriate situations, consequently also reflecting successful courtship of oestrus females, which would explain the high percentage for oldest males.

Mounts and mount attempts were observed on only 9 occasions, involving one 2-year-old, 4 males 3-4 yrs old, 2 males $5-6$ yrs old male, and 2 males $\geq 7$ yrs old. In one case, the ewe copulated with four $\geq 7.5 \mathrm{yrs}$ old rams which impeded one 3.5-year-old and two yearling rams from approaching her (Bon et al. 1992).

\section{Proportion of time dedicated to activity categories}

Time spent feeding decreased with male age; males $\geq 5.5$ yrs old fed two fold less than males $\leq 2.5$ yrs old (Fig. 4). Time spent standing increased with male age. Males 5.5-6.5 yrs old dedicated more time than older males to this activity, thus they fed and moved less. There was a tendency for males to move more with age. As a consequence, males decreased their time involved in energy intake (feeding) while increasing time in activities that consumed energy.
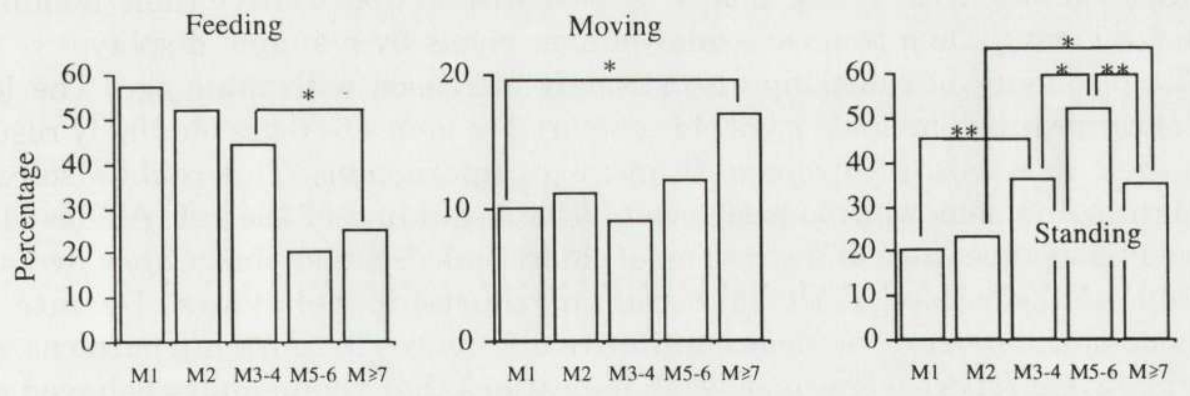

Fig. 4. Percentage of time dedicated by each age class to feeding, moving and standing. (Mann-Whitney test: ${ }^{*}-p<0.05,{ }^{* *}-p<0.01,{ }^{* * *}-p<0.001$ ). 


\section{Discussion}

Male mouflons may live up to 13 years old in this study area as revealed by trophies of hunted males (J. M. Cugnasse, unpubl.). Thus, estimated proportions of males $\geq 7.5$ years old (expected mid-life) suggest that the demography of the Caroux-Espinouse male mouflon population was biased toward young classes. This seems in accord with the mean age of males culled during the last $11 \mathrm{yrs}$ preceding this study. Previous analyses also agreed with this assumption (Bon et al. 1992).

In this study, males less than 2 yrs old rarely interacted with other males. They were clearly involved more in submissive, and less in dominant and risky interactions than older males, like Punjab urial Ovis orientalis punjabiensis, desert mule deer Odocoileus hemionus crooki and bison Bison bison (Schaller and Mirza 1974, Kucera 1978, Maher and Byers 1987). The rate of inter-male interactions increased with age, dramatically for males $\geq 7 \mathrm{yrs}$ old. Males 3 to $6 \mathrm{yrs}$ old submitted more and exhibited less dominant behavior patterns than males $\geq 7$ years. Males' interactions were not distributed equally among age classes. While submissive acts may involve males with large differences of age, dominant and especially risky behavior was preferentially addressed toward individuals of the same or similar age. This was previously shown in Punjab urial and moose Alces alces (Schaller and Mirza 1974, Peek et al. 1986). Conflicts would be avoided between animals distant in age as difference in body size would be a sufficient cue to dissuade the young from opposing the oldest males. Mature males would take more risks (although collective risky fights were rare) as their potential reproductive success is higher and less dependent on age, so that conflicts would be necessary to reveal dominance status (Clutton-Brock et al. 1979).

This study failed, however, to find clear qualitative differences in intra-sex interactions between males. Low samples do not allow us to draw conclusions on males 2 yrs old. Males 3-4 yrs old were observed to approach or chase away more, and kick other males less than oldest ones. This may reflect a maturation change and greater ability to resolve inter-male conflicts as oldest males performed more displays compared to young males. It may also simply reflect their dominance status, allowing them to push aside younger rivals by a simple display.

The frequency of courtship also strongly increased with male age. The lower rate of courtship of males $\geq 7$ yrs old compared to males 5-6 yrs old likely resulted from their increased involvement in intra-sex interactions. This could also reflect our data being somewhat biased towards the beginning of the rut. Alados (1986) showed how percentage of aggression of oldest male Spanish ibex Capra pyrenaica peaked and reversed later in favour of courtship behaviors. Despite this methodological reserve, no clear qualitative differences in courtship patterns arose with male age. There were some weak indications that young males behaved more aggressively towards females than did the old males. Previously, Bon et al. (1992) showed that most ewes were tended by males 3 to 6 yrs old, less often by males 2 yrs old. The few successful mounts observed in this study confirm that result. 
Some papers report differences in courtship with male age in ungulates (Ozoga and Verme 1985, Alados 1986, Barrette 1987, Habibi 1987). However, male courtship may be dependent upon the presence of dominant males. In the absence of the largest rams, younger ones were shown to exhibit the same courtship as the oldest (Shackleton 1991). Our results seem to confirm Shackleton's (1991) hypothesis which predicted that when old males are absent or rare, as in the Caroux-Espinouse population, males' behavior may mature faster. Shackleton concluded that the behavioral maturation was not only age dependent but also depended on demographic constraints which affected individual growth and the social environment. Squibb (1985) even reported that yearling bull elk Cervus elaphus nelsoni were as capable as older bulls to achieve successful breeding in the absence of the older animals.

During the rut, older males reduced their energy intake and spent more time in competition and courting females (Clutton-Brock et al. 1982, Maher and Byers 1987, Singer et al. 1991). The oldest rams spent the shortest time in female company during the rut and their presence is strongly related to the peak of oestrus (Bon et al. 1992, 1993b). Various indices suggest that the level of competition is rather low in Caroux-Espinouse population. Our expectation that with less competition and greater access to estrous females, young males should be less inhibited and should increase their reproductive effort is not supported. Although we have no comparative situation, the young males were much less engaged in mating activities than large males despite sexual maturity at age 1.5. Significant participation in rut activities obviously appear from 3 years old on. Singer et al. (1991) found that 3/4-curl younger rams had similar rate of ram-to-ram and ram-to-ewe displays whether older rams were present or not. Lower investment in rutting activity is also confirmed by the low percentage of young males seen alone in our study area, which is related to the search for receptive females (Barnes 1982, Poole 1989, Bon et al. 1993b).

It is commonly reported that male ungulates postpone their investment in reproduction because the costs associated with early reproduction exceed the benefits (Clutton-Brock et al. 1979, Dunbar 1982, Maher and Byers 1987, Kojola 1991). Theoretically, young rams should not oppose older dominant males because of high risks of injury and increased mortality during the subsequent winter. Because reproductive success was related to dominance which in turn depends on trophy and body size, young males would benefit by investing in body growth (Clutton-Brock et al. 1979).

A proximate explanation is that the level of reproductive effort of young males could depend on developmental constraints. This study presents clear evidence that the investment of time in rut activities is gradual. Young males have fewer fat reserves than older males because of somatic growth (Clutton-Brock et al. 1982, Kojola 1991, Shackleton 1991). The growth process would channel most of the energy intake, explaining why young males give priority to feeding activity (Gibson and Guinness 1980). High mortality rate and lower body growth in periods of 
lower feeding availability in juvenile ungulates support this hypothesis (Clutton-Brock et al. 1985, Festa-Bianchet 1989, Leberg and Smith 1993). Young males may be less motivated to court females than older males, which would be able to offset energy costs linked to mating effort by fat reserves. A differential physiological/behavioral development hypothesis has been suggested to explain the difference of behavior between yearling and older white-tailed bucks Odocoileus virginianus (Ozoga and Verme 1985). Similarly, exhausted dominant males which dedicated most of their time in tending females become unable to defend them and are replaced by competitors (Lott 1979, Clutton-Brock et al. 1982). Murphy et al. (1990) did not find reduced survival of young Dall rams with hunt-reduced old rams. They suggested that, despite higher access to reproduction, young males could not modify their general activity enough to impair their survival. Our mount data show that young males may successfully breed. But they were weakly involved in ram-ram interactions, and then probably avoided high energy losses that are associated with fights mainly observed with larger rams (Murphy et al. 1990).

Young male reproductive effort may be distributed over a larger period that old males. Indeed, they stay longer time in female groups, arriving soon in the pre-rut and staying during the late rut when some females are mated (Bon et al. $1993 \mathrm{a}, \mathrm{b})$. Unfortunately, for the reason mentioned before, our data did not allow us to compare pre-rut and full rut periods. Thus we cannot discard a possible investment of time by young males at the beginning of the rut when old males are rare and/or an investment by young males during a longer period of time than old males, resulting in similar appraisal of energy losses between age classes. Nonetheless, our observations in the beginning of December reveal that young males interacted very little with females, and dedicated most of their time to feeding. During this month, mean group size increased to reach the highest values of the year which continued through January, suggesting a period of social stability (Bon et al. 1993b).

Acknowledgments: This study was supported by a French-Spanish "Action Intégrée" n- 40/208. RB was supported by pre-doctoral and post-doctoral grants provided by the Spanish Ministry of Educacion and Sciences (Estancias temporales de Cientificos Extranjeros en España) and by a French Foreign Office post-doctoral grant (Programme Lavoisier). We thank M. D. Bosch, S. Carpintero, F. Castro, I. Estevez and M. L. Maublanc for help in collecting data. M. Festa-Bianchet, D. M. Shackleton and two anonymous referees made constructive remarks and criticisms. This paper was partly writen during a post-doctoral stay in the Centre de Recherche en Ecologie, Nutrition et Energétique. RB was supported by a French-Spanisch "Action Intégrée", MAE (programme Lavoisier) and MEC (Estancias de Cientificos y Tecnólogos extranjeros en España) post-doctoral grants.

\section{References}

Alados C. L. 1986. Aggressive behaviour, sexual strategies and their relation to age in male Spanish ibex (Capra pyrenaica). Behavioural Processes 12: 145-158.

Altmann J. 1974. Observational study of behavior: sampling methods. Behaviour 49: 227-267. 
Barnes R. F. W. 1982. Mate searching behaviour of elephant bulls in a semi-arid environment. Animal Behaviour 30: 1217-1223.

Barrette C. 1987. Mating behaviour and mate choice by wild axiz deer in Sri Lanka. Journal of Bombay Natural History Society $84: 361-371$.

Bon R., Dardaillon M. and Estevez I. 1993a. Mating and lambing periods as related to age of female mouflons. Journal of Mammalogy 74: 752-757.

Bon R., Gonzalez G., Bosch M. D. and Cugnasse J. M. 1992. Ram rut-involvement in a hunted population of mouflons. Acta Theriologica 37: 63-71.

Bon R., Maublanc M. L., Badia J. and Recarte J. M. 1993b. Population structure and social grouping of mouflons during the rut. Zeitschrift für Säugetierkunde 58: 294-301.

Byers J. A. and Kitchen D. W. 1988. Mating system shift in a pronghorn population. Behavioural Ecology and Sociobiology 22: 355-360.

Carranza J., Alvarez F. and Redondo T. 1993. Territoriality as a mating strategy in red deer. Animal Behaviour 40: 79-88.

Cavallini P. 1987. On the behaviour of male Sardinian mouflons (Ovis orientalis musimon) during the pre-rut. Mammalia 51: 195-200.

Clutton-Brock T. H., Albon S. D., Gibson R. M. and Guinness F. E. 1979. The logical stag: adaptative aspects of fighting in red deer (Cervus elaphus L.). Animal Behaviour 27: 211-225.

Clutton-Brock T. H., Albon S. D. and Guinness F. E. 1985. Parental investment and sex differences in juvenile mortality in birds and mammals. Nature 313: 131-133.

Clutton-Brock T. H., Guinness F. E. and Albon S. D. 1982. Red deer. Behavior and ecology of two sexes. Edimburgh University Press, Edimburgh: 1-378.

Dunbar R. I. M. 1982. Intraspecific variations in mating strategy. [In: Perspectives in ethology. P. P. G. Bateson and P. H. Klopfer, eds], vol. 5. Plenum Press, New York: 385-431.

Festa-Bianchet M. 1989. Survival of male bighorn sheep in southwestern Alberta. Jornal of Wildlife Management 53: 259-263.

Geist V. 1969. On delayed social and physical maturation in mountain sheep. Canadian Journal of Zoology 46: 899-904.

Gibson R. M. and Guinness F. E. 1980. Differential reproduction among red deer (Cervus elaphus) stags on Rhum. Journal of Animal Ecology 49: 199-208.

Gosling L. M. 1991. The alternative mating strategies of male topi, Damaliscus lunatus. Applied Animal Behavioural Sciences 29: 107-119.

Habibi K. 1987. Behavior of aoudad (Amotragus lervia) during the rutting season. Mammalia 51: 497-513.

Heimer W. E., Watson S. M. and Smith T. C. 1984. Excess ram mortality in a heavily hunted dall sheep population. Symp. North. Wild sheep and Goat Counc. 4: 425-432.

Hogg J. T. 1984. Mating in bighorn sheep: multiple creative male strategies. Science 225: 526-529.

Hogg J. T. 1987. Intrasexual competition and mate choice in Rocky mountain bighorn sheep. Ethology 75: $119-144$

Kojola I. 1991. Influence of age on the reproductive effort of male reindeer. Journal of Mammalogy 72 : 208-210.

Kucera T. E. 1978. Social behavior and breeding system of the desert mule deer. Journal of Mammalogy 59: 463-476.

Langbein J. and Thirgood S. J. 1989. Variation in mating systems of fallow deer (Dama dama) in relation to ecology. Ethology 83: 195-214.

Leberg P. L. and Smith M. H. 1993. Influence of density on growth of white-tailed deer. Journal of Mammalogy 74: 723-731.

Lott D. F. 1979. Dominance relationships and breeding rate in mature male American bison. Zeitschrift für Tierpsychologie 49: 418-432.

Lott D. F. 1984. Intraspecific variation in the social systems of wild vertebrates. Behaviour 88: $266-325$ 
Maher C. and Byers J. A. 1987. Age-related changes in reproductive effort of male bison. Behavioural Ecology and Sociobiology 21: 91-96.

McClelland B. E. 1991. Courtship and agonistic behavior in mouflon sheep. Applied Animal Behavioural Sciences 29: 67-85.

Murphy E. C., Singer F. J. and Nichols L. 1990. Effects of hunting on survival and productivity of Dall sheep. Journal of Wildlife Management 54: 284-290.

Ozoga J. J. and Verme L. J. 1985. Comparative breeding behavior and performance of yearling vs. prime-age white-tailed bucks. Journal of Wildlife Management 49: 364-372.

Peek J. M., Van Ballenberghe V. and Miquelle D. G. 1986. Intensity of interactions between rutting bull moose in central Alaska. Journal of Mammalogy 67: 423-426.

Poole J. H. 1989. Mate guarding, reproductive success and female choice in African elephants. Animal Behaviour 37: 842-849.

Rubenstein D. I. 1986. Ecology and sociality in horses and zebras. [In: Ecological aspects of social evolution. Birds and mammals. D. I. Rubenstein and R. W. Wrangham, eds]. Princeton University Press, Princeton: 282-302.

Schaller G. B. and Mirza Z. B. 1974. On the behavior of Punjab urial (Ovis orientalis punjabiensis). [In: The behaviour of ungulates and its relation to management. V. Geist and F. Walther, eds]. IUCN, n- 24, Morges, Switzerland: 306-323.

Shackleton D. M. 1991. Social maturation and productivity in bighorn sheep: are young males incompetent? Applied Animal Behavioural Sciences 29: 173-184.

Singer F. J., Murphy E. C., Cooper B. A. and Laing K. K. 1991. Activity in a hunted and an unhunted herd of Dall sheep. Applied Animal Behavioural Sciences 29: 185-193.

Squibb R. C. 1985. Mating success of yearling and older bull elk. Journal of Wildlife Management 49: 744-750.

Thirgood S. J. 1990. Alternative mating strategies and reproductive success in fallow deer. Behaviour 116: 1-10.

Valdez R., Cardenas M. and Sanchez J. 1991. Disruptive mating behavior by subadult Armenian wild sheep in Iran. Applied Animal Behavioural Sciences 29: 165-171.

Received 14 March 1994, revised 3 April 1995, accepted 7 June 1995. 